\title{
Prospective Evaluation of Antibiotic Prophylaxis for Preventing Symptomatic UTI before Cystoscopy in Adults: Should We?
}

\author{
M. Prasada Rao ${ }^{1}$, M. Sudarsana Rao², M. Monica Reddy³, YB Vamsi Krishna4, M.Roja Sushmita ${ }^{5}$ \\ ${ }^{1}$ Associate Professor, Urology Division, Department of General Surgery, NRI Institute of Medical Sciences, Sangivalasa, \\ Visakhapatnam, Andhra Pradesh, ${ }^{2}$ Assistant Professor, Department of Urology, AMC, King Geroge Hospital, Visakhapattanam, \\ A.P., ${ }^{3}$ Post Graduates, Department of General Surgery, NRIIMS, ${ }^{4}$ Post Graduates, Department of General Surgery, NRIIMS, \\ ${ }^{5}$ (Medico), NRIIMS, India
}

Corresponding author: M. Prasada Rao, Vizag Kidney and Urology Centre, MIG 55, Sector 5, Beside Punjab National Bank, MVP Colony Double Road, Visakhapattanam, A.P., India

DOI: http://dx.doi.org/10.21276/ijcmsr.2020.5.2.17

How to cite this article: M. Prasada Rao, M. Sudarsana Rao, M. Monica Reddy, YB Vamsi Krishna, M.Roja Sushmita. Prospective evaluation of antibiotic prophylaxis for preventing symptomatic UTI before cystoscopy in adults: should we?. International Journal of Contemporary Medicine Surgery and Radiology. 2020;5(2):B72-B75.

\section{A B S T R A C T}

Introduction: Cystoscopy is commonly performed diagnostic procedure as outpatient setting. Regarding use of prophylactic antibiotic there is lot of ambiguity. The aim of the study was to find the incidence of symptomatic urinary tract infections with or without use of antibiotic prophylaxis for cystoscopy.

Material and methods: A total of 332 patients were grouped into A\&B. While group B (166 patients) received a single intravenous cefotaxime as antibiotic prophylaxis before cystoscopy. Pre- and post-operative urinalysis and culture were done in both groups. Patients were followed on first day and first week after the procedure and observed for any symptomatic or asymptomatic urinary tract infections.

Results: In both groups all preoperative parameters were well matched. Evaluation of lower urinary tract symptoms and haematuria were the major indications for cystoscopy. Symptomatic UTI developed in 6 (3.6\%) vs 5 (3.01\%) and asymptomatic bacteriuria developed in $25 \%$ vs $24 \%$ in both A and B groups respectively. Statistically no significance difference among them. Conclusion: The present study proved that there is no significant difference in developing symptomatic urinary tract infections with or without the antibiotic prophylaxis. However antibiotic stewardship should be there in health care institutes in view of the emerging antibiotic resistance organisms, cost and adverse reactions.

Keywords: Cystoscopy; Antibiotic Prophylaxis; Bacteriuria; Urinary Tract Infections.

\section{INTRODUCTION}

Maximilian Carl-Friedrich Nitze a German urologist in collaboration with Joseph Leiter developed the first true working cystoscope in $1878 .{ }^{1}$ Cystourethroscopy is one of the most common procedures performed by a urologist. Diagnostic cystoscopy is commonly performed during evaluation of hematuria, evaluation \& surveillance of malignancy, and to evaluate lower urinary tract symptoms (LUTS) in both male and females.

Antibiotic prophylaxis is used to minimize infectious complications resulting from interventions. Cystoscopy like other endo-urological procedures considered as clean contaminated (Class II) surgery. ${ }^{2}$ However, evidence in the literature revealed that urological instrumentation is associated with increased incidence of urinary tract infection and bacteraemia. ${ }^{3}$ Potential sources of bacteria leading to infection include urethral flora, the prostatic adenoma, bladder colonization, or perioperative contamination. ${ }^{4,5}$ The potential side effects and the development of microbial resistance pattern rationalize the usage of antibiotics. ${ }^{6,7}$ Most of the urologist world-wide use antibiotics before cystourethroscopy with the fear of iatrogenic urinary tract infections though some studies and guidelines envisage routine prophylactic use not necessary. ${ }^{3,8}$ So, there is lot of ambiguity in usage of antibiotics.

We prospectively conducted a study by using a single dose of pre procedural antibiotic prophylaxis and without it; to evaluate the occurrence of symptomatic urinary tract infections in different diagnostic cystoscopic procedures.

\section{MATERIAL AND METHODS}

We conducted a prospective randomized study between march 2014 to April 2018. All the eligible patients are randomly grouped into two by using a computer software programme. Of which group A not received any drug while group B received a single dose intravenous third generation cephalosporin Cefotaxime $1 \mathrm{gm}$ just before cystoscopy.

All the patients were evaluated before cystoscopy. Detailed clinical history especially focussing on dysuria, fever, loin pain, renal angle and supra pubic tenderness were taken. The indication for cystoscopy, any comorbid illnesses and any prior usage of antibiotic were noted. Mid-stream urine collected for microscopy and culture before, at first post- 
operative day, and first week after the procedure. Any pyuria and bacteriuria noted specifically.

The patients which we included in this study were

1. To evaluate LUTS (lower urinary tract symptoms)

2. To evaluate patients of recurrent UTI, CPPS, SUI etc.

3. To evaluate gross and microscopic hematuria

4. Surveillance or evaluation of malignancy (bladder, urethra, abnormal urinary cytology, upper tract TCC etc...)

The following patients were excluded:

1. Patients with active UTI, with culture positivity

2. Who received antibiotic for any other purpose at least one week before

3. Any patients requiring IE prophylaxis

4. Known sensitivity to cephalosporins/penicillin

All the patients were explained the procedural details, possible complications of procedure and informed written consent was taken. Local hospital ethical committee approval was taken before the study. All the patients were followed up at first post op day and first week following the procedure.

Systemic and localized UTI were taken as study primary outcome and asymptomatic bacteriuria as secondary outcome for evaluation purpose.

Systemic UTI defined as sepsis, fever $\geq 38^{\circ} \mathrm{C}$ and documented bacteriuria. Significant bacteriuria is defined as midstream urine culture with more than $10^{5}$ colony forming units $(\mathrm{CFU}) / \mathrm{mL})$

Localised UTI defined as local symptoms such as urinary irritative symptoms, dysuria, suprapubic pain, and documented significant bacteriuria.

Asymptomatic bacteriuria defined colony count of less than $10^{5}$ without any local or systemic symptoms.

Post cystoscopy all patients were followed with telephone call to enquire about their symptoms if any.

Cystoscopy procedure done in operation theatre. After lithotomy position, parts prepared using $5 \%$ povidone iodine solution followed by chlorhexidine solution and draped with sterile cloths exposing only genitalia. $2 \%$ xylocaine jelly used as topical anaesthesia. If needed we took the help of anaesthetist for short general anaesthesia in very apprehensive patients. We used 19F Karl Storz (Tuttlingen, Germany) rigid cystoscope sheath and 30-degree Hopkins lens system with normal saline as irrigation solution. The surgical instruments were made sterile by soaking them in $2 \%$ glutaraldehyde (Cidex) solution at least half an hour before using them.

\section{STATISTICAL ANALYSIS}

Results are expressed as mean $\pm \mathrm{SD}$. Comparison between the two groups performed using unpaired $t$ test. The data were considered significant if $\mathrm{p}$-value was $\leq 0.05$ through $\mathrm{Chi}$ square test. Statistical analysis was performed with the aid of the SPSS computer program (version 12 windows).

\section{RESULTS}

396 patients were evaluated out of which 332 patients were eligible and enrolled into the study and they were allocated into group A \& B,166 patients in each group. The demographic date is given in table 1 . Patients were

\begin{tabular}{|l|c|c|}
\hline Variable & $\begin{array}{c}\text { Group A } \\
\text { (No antibiotic) }\end{array}$ & $\begin{array}{c}\text { Group B } \\
\text { (antibiotic) }\end{array}$ \\
\hline Number of Patients & 166 & 166 \\
\hline Mean Age (SD) & $49.02(12.2)$ & $52.40(16.4)$ \\
\hline Sex - male/female & $114 / 52$ & $110 / 56$ \\
\hline Diabetics & 35 & 39 \\
\hline \multicolumn{3}{|c|}{ Table-1: } \\
\hline
\end{tabular}

\begin{tabular}{|l|c|c|}
\hline Indication & A & B \\
\hline LUTS & 65 & 54 \\
\hline Hematuria & 50 & 45 \\
\hline VVF & 5 & 9 \\
\hline Surveillance (Check) cystoscopy & 25 & 24 \\
\hline Miscellaneous & 7 & 18 \\
\hline Cold cup biopsy & 14 & 16 \\
\hline \multicolumn{2}{|c|}{ Table-2: shows the indication for the cystoscopy. } \\
\hline
\end{tabular}

\begin{tabular}{|l|c|c|c|}
\hline & A & B & P \\
\hline Symptomatic UTI (\%) & $6(3.61)$ & $5(3.01)$ & $>0.05$ \\
\hline Asymptomatic Bacteriuria (\%) & $41(25)$ & $40(24)$ & $>0.05$ \\
\hline \multicolumn{4}{|c|}{ Table-3: shows the details of UTI } \\
\hline
\end{tabular}

comparable in their demographic pattern.

In our study diagnostic cystoscopy for evaluating lower urinary tract symptoms and hematuria were occupied most. Evaluating stress urinary incontinence (SUI) and chronic pelvic pain syndrome (CPPS), chyluria and ruling out recurrent UTI were considered as miscellaneous.

In group A 6 patients developed culture proven localized UTI and 5 patients in group B, statistically they were not significant. All these patients were symptomatic with dysuria, suprapubic pain and irritative LUTS. One patient in group B developed systemic UTI with fever at one-week post procedure. He was diabetic and relieved of his illness with systemic culture specific antibiotics. The most frequent organisms were E. coli and the minority are Klebsiella Pneumonia and Enterococci. Almost all of them are sensitive to drug Amikacin, and having various sensitivity pattern with other drugs like amoxycillin based, piperacillin based, imipenem and nitrofurantoin.

41 patients (24.69\%) patients in group A and 40 (24.09\%) in group B had asymptomatic bacteriuria in first week. But few of them had irritative symptoms which could be managed with bladder specific anticholinergics without any antibiotics. These are the patient who had received radiotherapy for various indications. Fifty percent of these patients are significant pyuria and microscopic hematuria. All patients in whom cold cup biopsy showed asymptomatic bacteriuria with pyuria and microscopic hematuria.

\section{DISCUSSION}

Ever since visualizing body cavities after the first invention of primitive scope by Phillip Bozzini, a German army surgeon, in 1806, many technological advancements have come to visualize almost all organs of the body. In this effort cystoscopy is one of the primitive endoscopic procedures employed by him. Cystoscopy is one of the commonest 
ambulatory procedure done by urologists across the globe and is performed mostly a diagnostic tool. Any mucosal (cystoscopy) intervention may leads to invasion by local organisms and may lead to infections. Few studies emphasize antibiotics are required to combat symptomatic UTI after cystoscopy. ${ }^{9,10}$ Previous studies have shown that a single dose of prophylactic antibiotic can significantly reduce the risk of bacteriuria after cystoscopy. Johnson in his study suggested that one dose of oral antibiotic could, not only lower costs, but also reduce the risks of drug resistance. But majority of the studies disagree about this contention. ${ }^{9}$ Garcia-Perdomo found prophylactic antibiotic could not significantly reduce UTI of patients undergoing cystoscopy compared with placebo. ${ }^{11}$

In our present study there was no statistical difference among demographic data and preprocedural indications of cystoscopy. This study proved that whether use of antibiotic or not doesn't have significance in terms of causing symptomatic UTI. There was a nice Cochrane database review about usage of antibiotics before cystoscopy. ${ }^{12}$ In our study both groups have $3.61 \%$ and $3.01 \%$ of infections. In one of the studies the rate of post-cystoscopy symptomatic UTI is just $3.7 \% .^{13}$ Less than 5 percent risk of symptomatic UTI is acceptable according to the study by Her. ${ }^{14}$ Similarly, other studies also prove the overall infection rate was less significant in both arms. ${ }^{15,16}$

Only one patient in group B developed systemic UTI and he was a diabetic. So it was obvious that antibiotic prophylaxis may not reduce the systemic UTI. There is one recent Cochrane database emphasises this. ${ }^{17}$

Our study revealed that though symptomatic UTI is same as in many of the previous studies, but pyuria and asymptomatic bacteriuria is seen in good number of patients (up to 25\%). This may be because of the invasiveness by endoscopic instruments and by the periurethral colonizing organisms . Garcia-Perdomo study revealed the incidence of asymptomatic bacteriuria after cystoscopy ranges from $2.8 \%$ to $21 \%{ }^{11}$ Another study also showed the incidence of asymptomatic bacteriuria between $10-35 \% .^{18}$

The most common bacteria isolated was E.coli., Klebsiella Pneumonia. These are the most common uro pathogens world wide. Because of the antibiotic abuse worldwide, the susceptibility rates of antibiotics to E.coli are ranging from about $60 \%$ to nearly $70 \%$ (cefuroxime $67.8 \%$ to $86.4 \%$, ciprofloxacin $61.2 \%$ to $69.8 \%$ and co-trimoxazole $55.0 \%$ to $65.5 \%)(19,20)$

\section{CONCLUSION}

Cystoscopy is a very common endoscopic procedure done by urologists and also some general surgeons. Our study reiterates that there is no significant benefit of using antibiotics prophylactically for cystoscopy especially when there is no significant bacteriuria before the procedure. These are in accordance to the guidelines laid down by the panel of 'American Urological Association' on usage of antibiotics in urological infections. ${ }^{21}$ Antimicrobial prophylaxis should be recommended in clinical practice when the potential benefit outweighs the risks, costs and bacterial resistance patterns through antibiotic stewardship.

\section{REFERENCES}

1. Ramai D, Zakhia K, Etienne D, Reddy M. Philipp Bozzini (1773-1809): The earliest description of endoscopy. J Med Biogr. 2018;26(2):137-141.

2. Mangram, AJ, Horan, TC, Pearson, ML, et al: Guideline for prevention of surgical site infection. Am J Infect Control 1999; 27(5): 97.

3. Childs SJ. Appropriate surgical prophylaxis in transurethral genitourinary surgery and potential reduction in nosocomial infections. Urology 1986;27(4):415-20.

4. Qiang W, Jianchen W, MacDonald R, Monga M, Wilt TJ. Antibiotic prophylaxis for transurethral prostatic resection in men with preoperative urine containing less than 100,000 bacteria per ml: A systematic review. J Urol 2005;173(6):1175-8.

5. Goldwasser B, Bogokowsky B, Nativ O, Sidi AA, Jonas P, Many M. Urinary infections following transurethral resection of bladder tumors: Rate and source. J Urol 1983;129(5):1123-4

6. Mirone V, Franco M.Clinical aspects of antimicrobial prophylaxis for invasive urological procedures.J Chemother. 2014;26 Suppl 1:S1-S13.

7. Ivan SJ, Sindhwani P. Comparison of guideline recommendations for antimicrobial prophylaxis in urologic procedures: variability, lack of consensus, and contradictions.Int Urol Nephrol. 2018;50(11):19231937.

8. Turan H, Balci U, Erdinc FS, Tulek N, Germiyanoglu C. Bacteriuria, pyuria and bacteremia frequency following outpatient cystoscopy. Int J Urol 2006;13(1):25-8.

9. Johnson MI, Merrilees D, Robson WA, Lennon T, Masters J, Orr KE, et al. Oral ciprofloxacin or trimethoprim reduces bacteriuria after flexible cystoscopy. BJU International 2007;100(4):826-9.

10. Rané A, Cahill D, Saleemi A, Montgomery B, Palfrey E. The issue of prophylactic antibiotics prior to flexible cystoscopy. European Urology 2001;39(2):212-4.

11. Garcia-Perdomo HA, Lopez H, Carbonell J, Castillo D, Catano JG, Seron P. Efficacy of antibiotic prophylaxis in patients undergoing cystoscopy: a randomized clinical trial. World Journal of Urology 2013;31(6):1433-9.

12. Shuxiong Zeng, Zhensheng Zhang, Yu Bai, Yinghao Sun, Chuanliang $\mathrm{Xu}$. Antimicrobial agents for preventing urinary tract infections in patients undergoing cystoscopy. Cochrane database Systematic Reviews 2016 (8): 10/1002/14654858.CD012305

13. 13. Herr HW. The risk of urinary tract infection after flexible cystoscopy in patients with bladder tumor who did not receive prophylactic antibiotics. Journal of Urology 2015;193(2):548-51.

14. Herr HW. Should antibiotics be given prior to outpatient cystoscopy? A plea to urologists to practice antibiotic stewardship. European Urology 2014;65(4):839-42.

15. Herney Andres Garcia-Perdomo HA, Eladio JimenezMejias Hugo Lopez-Ramos Efficacy of Antibiotic Prophylaxis in Cystoscopy to Prevent Urinary Tract Infection: A Systematic Review and Meta-Analysis. Int 
Braz J Urol 2015;41(3):412-24

16. Kraklau DM, Wolf JS Jr. Review of antibiotic prophylaxis recommendations for office-based urologic procedures. Tech Urol 1999;5(2):123-8.

17. Zeng S, Zhang Z, Bai Y, Sun Y, Xu Ch. Antimicrobial agents for preventing urinary tract infections in patients undergoing cystoscopy. Cochrane database Systematic Reviews 2019 (2) CD012305.

18. Dzelaludin Junuzovic D, Hasanbegovic M. Risk Factors Analysis for Occurrence of asymptomatic bacteriuria after endourological procedures. Med Arch. 2014; 68(4): 249-253.

19. Bakken JS. The fluoroquinolones: how long will their utility last?. Scandinavian Journal of Infectious Diseases 2004;36(2):85-92.

20. Sorlozano A, Jimenez-Pacheco A, Dios Luna Del Castillo J, Sampedro A, Martinez-Brocal A, MirandaCasas $\mathrm{C}$, et al. Evolution of the resistance to antibiotics of bacteria involved in urinary tract infections: a 7 year surveillance study. American Journal of Infection Control 2014;42(10):1033-8.

21. Lightner DJ, Wymer K, Sanchez J, Kavoussi L. Urological procedures and antimicrobial prophylaxis. AUA guildlines, 2019.

Source of Support: Nil; Conflict of Interest: None

Submitted: 22-04-2020; Accepted: 17-05-2020; Published online: 15-06-2020 